\title{
A VIVÊNCIA DE MULHERES NO PARTO DOMICILIAR PLANEJADO
}

\author{
WOMEN'S EXPERIENCE IN A \\ PLANNED HOME BIRTH
}

\section{Rosimery Barão Kruno', Tatiane Osvaldt da Silva², Patrícia Taís de Oliveira Trindade²}

\section{RESUMO}

Objetivou-se conhecer a vivência de mulheres que tiveram partos domiciliares planejados e desvelar os motivos dessa opção. Estudo qualitativo que entrevistou oito mulheres cujos partos domiciliares foram planejados. A coleta de dados ocorreu através de entrevista semi-estruturada em outubro de 2014. A análise dos dados baseou-se no método temático de onde emergiram as categorias e subcategorias: (a) Motivações para o parto domiciliar, (b) Vivenciando o parto domiciliar: (b1) Empoderamento e transformação, (b2) Aliviando a dor, (b3) Corte tardio do cordão umbilical (b4), Placenta e ancestralidade; (c) A família e o parto domiciliar. As motivações para o parto domiciliar envolveram oposição às rotinas hospitalares e a falta de privacidade e autonomia da parturiente sobre seu corpo e seu filho. As vivências foram descritas como empoderadoras, conferindo-lhes maior valorização familiar. $O$ parto domiciliar planejado é uma realidade crescente no Brasil, devido à divulgação de evidências científicas obstétricas e relatos bem-sucedidos. A mulher atual busca uma vivência de parto que transcenda o aspecto biológico.

Descritores: Humanização do Parto; Parto Domiciliar; Saúde da Mulher; Enfermeira Obstétrica.

\section{ABSTRACT}

This study aimed to know the experience of women who had planned home births and reveal the reasons for their choice. This qualitative study interviewed eight women whose home births were planned. The data was collected through semi-structured interviews in October 2014. Data analysis was based on thematic approach from where the following categories and subcategories emerged: (a) Motivations for home birth, (b) Experiencing home birth : (b1) Empowerment and transformation, (b2) Relieving the pain, (b3) Delayed cord clamping (b4), Placenta and ancestry; (c) The family and the home birth. The motivations for homebirth involved opposition to hospital routines and the lack of privacy and autonomy of the woman in labor on her body and her child. The experiences were described as empowering, giving them more family value. The planned home birth is a growing reality in Brazil, due to the dissemination of obstetric scientific evidence and successful accounts. Modern women seek a birth experience that transcends the biological aspect.
${ }^{1}$ Mestre em Enfermagem pela Universidade Federal do Rio Grande do Sul (UFRGS), Porto Alegre, RS, Brasil.

2 Graduanda do Curso de Enfermagem no Centro Universitánio La Salle (UNILASALLE), Canoas, RS, Brasil.

Descriptors: Humanized Delivery; Home Birth; Women's Health; Obstetric Nurse. 


\section{Introdução}

Houve um tempo em que os partos ocorriam predominantemente no domicílio e isso era visto com naturalidade pela sociedade no início do século passado. Mas, desde o advento das maternidades institucionalizadas, a partir da Segunda Guerra Mundial, os nascimentos passaram a ocorrer cercados por rotinas rígidas, desconsiderando a individualidade de cada mulher. A impessoalidade dos profissionais frente à demanda de trabalho e o excesso de intervenções levaram rapidamente à desumanização da assistência e até mesmo ao fenômeno da violência obstétrica.

O parto domiciliar planejado tem sido uma tendência crescente entre as mulheres brasileiras nos últimos anos. A rápida disseminação de informações pela internet, as ações procedentes das políticas públicas que prezam pela humanização do nascimento e a divulgação de estudos baseados em evidências científicas na área obstétrica favorecem a opção por dar à luz em casa.

Os dados mostram que ainda é pequeno o percentual de partos domiciliares no Brasil. Em geral, representam nascimentos de urgência, sem planejamento e que ocorrem em lugares onde o acesso ao serviço de saúde é tardio e deficiente. No entanto, dentro dessa pequena parcela de partos não institucionalizados existe um percentual de nascimentos que são assistidos por profissionais de saúde habilitados e que são planejados antecipadamente para acontecerem em domicílio. As estatísticas não são fidedignas sobre o número exato de partos domiciliares planejados, já que os sistemas de informações não discriminam quais partos foram realmente planejados ou não $0^{1,2}$.

Em alguns países, a prática de partos domiciliares já está oficializada e é, inclusive, incentivada pelo sistema de saúde, tais como o Canadá e a Austrália. Na Holanda, $40 \%$ dos partos ocorrem no domicílio com resultados perinatais satisfatórios 3 .

No Brasil, entidades da classe médica são resistentes ao parto em ambiente doméstico, alegando que o parto fora do hospital expõe a parturiente e a criança a riscos que podem ser evitados ou problemas que facilmente podem ser solucionados dentro de um centro obstétrico, por conta da imprevisibilidade das circunstâncias.

Uma revisão sistemática publicada em 2012, sobre 22 estudos observacionais comparou os resultados maternofetais procedentes de partos domiciliares com os resultados de partos hospitalares. Foi constatado que não houve diferença nos índices de mortalidade perinatal, considerando mulheres de risco habitual assistidas por profissionais capacitados ${ }^{4}$.

As evidências científicas têm confirmado que o parto domiciliar é seguro, desde que a gestação seja de risco habitual, os profissionais sejam qualificados e exista um planejamento prévio, caso seja necessária uma transferência para o hospital ${ }^{5}$.

O fato é cada vez mais as mulheres têm divulgado suas experiências satisfatórias de partos domiciliares planejados, influenciando outras mulheres a buscarem o mesmo caminho. Esse estudo se propôs a conhecer as razões para essa escolha, além de desvelar mais detalhes sobre suas vivências de partos em casa.

\section{Metodologia}

Trata-se de uma pesquisa qualitativa que buscou conhecer a vivência de mulheres que optaram por partos domiciliares planejados e desvelar os motivos dessa escolha.

O projeto deste estudo foi aprovado pelo Comitê de Ética e Pesquisa (CEP) do Unilasalle/RS em 06 de outubro de 2014, sob o $n^{0}$ do Parecer 820.829. Os dados foram coletados no transcorrer do mesmo mês, na casa de cada depoente, mediante combinações prévias.

Foram entrevistadas oito mulheres residentes na cidade de Porto Alegre/RS e que participaram de um grupo de incentivo ao parto humanizado, denominado "Saber Materno", ao qual uma das pesquisadoras visitou antecipadamente. Dessas, duas serviram como teste piloto, a fim de averiguar-se a qualidade do instrumento de coleta. 0 número máximo de participantes ficou na dependência da saturação dos dados. Esse fenômeno ocorre quando o pesquisador percebe que as informações de novos participantes não mais contribuem para a análise, limitando aí o número de entrevistadas ${ }^{6}$.

As mulheres foram escolhidas aleatoriamente, porém respeitando os seguintes critérios de inclusão: residir em Porto Alegre; ter, no mínimo, 18 anos completos; ter vivenciado o parto domiciliar planejado há pelo menos três meses por estarem mais adaptadas às rotinas com o bebê e, no máximo, há dois anos para que as lembranças das vivências estivessem mais afloradas; que participassem do estudo de modo voluntário, assinando o Termo de Consentimento Livre e Esclarecido em duas vias de igual teor. Foram respeitados todos os aspectos éticos referentes à pesquisa envolvendo seres humanos, conforme a Resolução 466 de dezembro de 2012, do Conselho Nacional de Saúde que visa 
assegurar os direitos e deveres da comunidade científica, dos sujeitos da pesquisa e do Estado ${ }^{7}$. Os princípios de sigilo e anonimato foram considerados, substituindo os nomes das mulheres por códigos, tais como P1 (participante 1), P2, e assim sucessivamente.

As entrevistas foram individualizadas, guiadas por um instrumento contendo questões semiestruturadas e utilizando-se um aparelho gravador de voz. 0 tempo para cada entrevista não ultrapassou 60 minutos. A análise baseouse na proposta temática de Minayo, que consiste em descobrir os núcleos de sentido que compõem uma comunicação, cuja presença ou frequência signifiquem alguma coisa para o objeto analítico visado .

\section{Resultados e Discussão}

O estudo compreendeu, a partir da análise, a caracterização das participantes e as seguintes categorias e subcategorias: (A) Motivações para o parto domiciliar; (B) A vivência do parto domiciliar: (b1) empoderamento e transformação, (b2) recursos para o alívio da dor, (b3) corte tardio do cordão umbilical, (b4) placenta e ancestralidade; (C) Reação familiar frente ao parto domiciliar.

\section{Caracterização das participantes}

As mulheres que optaram por partos domiciliares possuem em média 26 anos de idade; quatro são primíparas e quatro multíparas. Quanto à escolaridade predominou o ensino superior incompleto. A maioria realizou em torno de dez consultas de pré-natal durante a gestação, número acima do mínimo recomendado pelo Ministério da Saúde. Os profissionais que estiveram presentes em seus partos foram, na maior parte das vezes, a parteira e a doula. Apenas duas referiram a presença de um médico. Vale ressaltar que frequentemente as enfermeiras obstétricas e as obstetrizes são denominadas de parteiras no vulgo popular.

O Ministério da Saúde denomina de parteira tradicional àquelas mulheres que prestam assistência ao parto baseadas em saberes e práticas tradicionais, sem possuir formação acadêmica. Em geral atuam em locais de difícil acesso aos serviços de saúde, tais como as comunidades rurais, indígenas, ribeirinhas ou quilombolas e não costumam ser remuneradas pelo seu trabalho ${ }^{3}$.

As enfermeiras obstétricas e as obstetrizes possuem formação acadêmica e remuneração específica. As primeiras realizam graduação em enfermagem e especialização na área obstétrica. As obstetrizes realizam a formação acadêmica em Obstetrícia. Tanto as enfermeiras obstétricas quanto as obstetrizes possuem em sua legislação profissional a permissão para atender ao parto sem distócia ${ }^{9}$.

\section{Motivações para o parto domiciliar}

As participantes do estudo optaram pelo parto domiciliar por oposição às práticas de rotina destinadas às parturientes e, especialmente, aos recém-nascidos nos centros obstétricos.

[...] eu não queria ir para o hospital, eu não queria ter intervenções como a episiotomia e as intervenções com o bebê como nitrato de prata, a aspiração e também o corte prévio do cordão umbilical. Eram coisas assim que eu sabia que no domiciliar seria bem diferente (P4)

[...] me dá pavor de pensar em procedimentos invasivos, em gente me abrindo, me espetando, me costurando (P8)

Uma pesquisa publicada em 2014 e denominada "Nascer no Brasil: Inquérito Nacional sobre Parto e Nascimento" constatou que, as gestantes que passam pelo parto normal nos hospitais brasileiros, são submetidas a um modelo de atenção extremamente medicalizado e intervencionista. A maioria das mulheres fica restrita ao leito, em jejum durante o trabalho de parto, recebe medicamentos para acelerar as contrações, passa por uma episiotomia, e dá à luz deitada de costas. Estes procedimentos causam dor e sofrimento desnecessários e não são recomendados pela Organização Mundial da Saúde (OMS) como rotina ${ }^{10}$. 
Além disso, estima-se que no Brasil, quase um milhão de mulheres ao ano são submetidas a cesarianas desnecessárias, e perdem a oportunidade de serem protagonistas do nascimento de seus filhos. Também são expostas, como eles, a maiores riscos de morbidade e mortalidade, aumentando os gastos com a saúde. Alguns estudos mostram, inclusive, as consequências da via de nascimento no curso natural do desenvolvimento intrauterino dos bebês e sobre sua saúde futura, incluindo o risco aumentado para obesidade, diabetes, asma e outras doenças ${ }^{10}$.

Não raro, a mulher que escolhe pelo parto em casa é considerada como irresponsável e adepta a um modismo, enquanto os profissionais envolvidos costumam ser perseguidos pelos seus próprios conselhos regulamentadores. A sociedade parece não compreender os motivos que levam essa mulher a abrir mão da suposta segurança hospitalar².

Tanto a OMS quanto o Ministério da Saúde afirmam que o parto domiciliar é tão seguro quanto o parto hospitalar, de acordo com resultados obstétricos advindos de pesquisas internacionais e nacionais, porém essas constatações não são amplamente divulgadas 5 .

Outro fator que influenciou as mulheres a buscarem o parto domiciliar foi a preocupação em manter um estilo de vida mais natural e saudável:

[...] sempre procuramos buscar uma assistência mais holística, a gente sempre se tratou com homeopatia, uma alimentação mais saudável. Esses cuidados eu continuei cultivando quando eu engravidei. Pra mim, era lógico que eu queria um parto sem intervenção (P3)

[...] sempre tive vontade de ter (parto) normal, que é essa coisa natural mesmo da mulher sentir as dores, de deixar acontecer, sem interferência hospitalar (P1)

Para as mulheres desse estudo, o parto é considerado um processo saudável, natural do corpo feminino que não requer nenhum tipo de intervenção desnecessária. A opção pelo parto em casa reforça essa convicção, pois consideram o hospital um local reservado aos casos especiais, de risco ou patologias comprovadas. Isso não significa que desejem um parto desassistido, já que, desde o pré-natal, buscam profissionais que lhes transmitam segurança, respeito e 0 direito de protagonizarem todo o processo.

As informações procedentes de livros, de grupos voltados ao parto natural e de relatos de partos domiciliares bem-sucedidos veiculados pela rede social também exerceram uma importante influência para essa escolha. É provável que o conhecimento seja uma das mais significativas ferramentas para a mudança de comportamento das mulheres com relação à parturição nos dias atuais e nos próximos anos. Com relação a isso, salienta-se o papel fundamental do enfermeiro durante o pré-natal, no sentido de oferecer orientações sobre os direitos das gestantes e puérperas e divulgar as principais evidências científicas disponíveis.

\section{A vivência do parto domiciliar}

Dessa categoria de análise emergiram outras quatro subcategorias: empoderamento e transformação, recursos para o alívio da dor, corte tardio do cordão umbilical e placenta e ancestralidade.

\section{Empoderamento e transformação}

Para as entrevistadas o parto domiciliar foi uma experiência pessoal transformadora, um rito de passagem, resultando em sensação de "empoderamento" diante da vida:

[...] Dar à luz um filho de forma natural, fisiológica, sem nenhum tipo de intervenção, é uma força tão transformadora que equivale a nascer novamente. Desde o meu parto me sinto tão poderosa, tão forte, tão mulher, segura e determinada que quase mais nada me amedronta. Me sinto pronta para viver de verdade (P8)

[...] hoje eu sou outra mulher, uma pessoa melhor e que tudo que eu passei, passaria de novo $(P 2)$ 
As mulheres que passaram por um parto natural em casa relatam claramente essa vivência de forma muito intensa. A ambiência da casa se sobressai como elemento de ancoragem que propicia ao mesmo tempo a livre expressão, segurança e intimidade, o que difere em muito daquilo que o ambiente hospitalar pode oferecer. Um centro obstétrico poderá dispor de um sistema de hotelaria atraente, mas dificilmente demandará a mesma energia do lar, simplesmente por ser um local estranho à mulher, desprovido de sua energia.

Os ritos de passagem são situações permeadas por símbolos, diretamente relacionadas à cultura e às crenças de uma pessoa ou coletividade. São dotados de grande significado, pois representam processos de transição, tais como: batismo, nascimento, casamento, formatura e funerais ${ }^{11}$.

Durante o trabalho de parto há predominância do "cérebro primitivo" em contrapartida ao neocórtex. Enquanto no primeiro predominam os instintos, no segundo, predominam as funções cognitivas. Para parir é preciso reduzir ao máximo os estímulos neocorticais para que a ocitocina e a endorfina acordem todos os mecanismos fisiológicos necessários ao nascimento. E, para reduzir as funções cognitivas é preciso que a mulher se sinta confortável e confiante para não colocar travas ao processo parturitivo ${ }^{12}$.

As palavras da $5^{\text {a }}$ participante ilustram a afirmação acima:

[...] parece que a gente entra num outro mundo e todas as emoções ficam afloradas dentro da gente, realmente é um momento muito único entre mãe e filho, parece que tudo fica sincronizado e cada um faz a sua parte durante o processo (P5)

[...] foram duas horas, mas pra mim parece que se passaram vinte minutos, tu entra numa partolândia, num outro mundo (P6)

Acrescido a isso, o reflexo de uma atenção de reverência à parturiente, dispensado pelos profissionais que a acompanham, fica registrado na memória das mesmas com extremo reconhecimento e consideração ${ }^{13}$.

[...] aí eu fui no chuveiro, a minha parteira entrou junto comigo me fazendo massagens (P4)

[...] o bebê ainda não tinha descido, daí fiquei muito na bola, no chuveiro, a doula e a enfermeira obstétrica, fantásticas, fizeram algumas manobras (P7)

Já o modelo tradicional de assistência ao parto é focado na redução dos riscos, na patologia e na falta de autonomia da mulher. Os profissionais podem ser afetuosos e competentes, mas ainda assim não serão suficientemente íntimos. Sob o ponto de vista fisiológico, isso é uma desvantagem ${ }^{10}$.

Os profissionais que acompanham os partos domiciliares parecem acessar o campo emocional e o campo mental das parturientes para que tudo ocorra em plena sintonia. As participantes relataram que as doulas e as parteiras não mediam esforços para ajudá-las a vivenciar o trabalho de parto de acordo com suas expectativas. Além disso, todas as entrevistadas referiram absoluta segurança na competência técnica dessas equipes.

Com relação à segurança do parto domiciliar, um grande estudo americano publicado em 2014, com 16.924 mulheres reforça o que outros estudos observacionais já haviam concluído anteriormente: no parto domiciliar há menores taxas de intervenções sem aumento do risco de complicações para mães e bebês, além do elevado grau de satisfação das usuárias ${ }^{14}$.

\section{Recursos para o alívio da dor}

Outra característica marcante em todas as entrevistadas é que elas já se encontravam bastante familiarizadas com os recursos que poderiam utilizar para o alívio da dor durante o trabalho de parto. As doulas foram as principais facilitadoras desse processo, supervisionando, sugerindo, promovendo materiais e conforto, sem tirar o poder decisório da parturiente. Entre os recursos mais utilizados foi o banho de aspersão e o de imersão.

As contrações vinham e eu entrava e saia da piscina [...] aí quando chegou meia noite e meia ele nasceu (P5) 
[...] dai começou as dores e eu fui pra banheira pra aliviar um pouco [...] e eu comecei a fazer as posições que eu tinha aprendido (P1)

Alguns estudos discorrem que a imersão em água quente é recomendada após os $5 \mathrm{~cm}$ de dilatação do colo uterino, promovendo o relaxamento e a redução da dor ${ }^{15}$.

E, para ajudar na descida da apresentação fetal referiram movimentos específicos com a pelve com ou sem o auxílio da bola.

$\mathrm{O}$ uso das grandes bolas de borracha tem sido utilizado durante 0 trabalho de parto com a finalidade de relaxar a musculatura, reduzir a dor, permitindo a mobilização da pele e auxiliando na descida da apresentação fetal. Embora não tenham sido encontrados estudos que demonstrassem evidências científicas quanto à redução da dor com o uso da bola, as mulheres podem ser encorajadas a utilizá-las a fim de encontrarem posturas mais confortáveis durante o trabalho de parto ${ }^{15}$.

\section{Corte tardio do cordão umbilical}

O corte tardio do cordão umbilical foi um aspecto muito destacado pelas mulheres, o que demonstrou estarem bem informadas sobre as principais evidências científicas relacionadas a essa conduta.

[...] 0 cordão umbilical foi cortado bem mais tarde quando já estava murchinho, ele em seguida já pegou o peito, enfim, deu tudo certo como eu planejava (P5) três horas (P4)

O clampeamento tardio do cordão umbilical, o contato imediato pele a pele e o início precoce da amamentação são práticas preconizadas pelas atuais "Diretrizes para a Organização da Atenção Integral e Humanizada ao Recémnascido pelo SUS". O pinçamento do cordão entre 2 e 3 minutos ou até que pare de pulsar aumenta o volume sanguíneo do bebê, conferindo-Ihe reservas de ferro por até 6 ou 8 meses de vida. Além disso, Ihe possibilita melhor adaptação cardiopulmonar ao nascer e maior sucesso na manutenção do aleitamento materno exclusivo ${ }^{15-17}$.

Entretanto, nos partos hospitalares, essa prática é insipiente e quem determina o tempo para o corte do cordão umbilical ainda são os profissionais. A grande demanda de tarefas a cumprir, o número reduzido de profissionais, a estrutura dos centros obstétricos podem contribuir, em parte, para essa restrição de tempo.

\section{Placenta e ancestralidade}

As participantes desse estudo relataram a prática da conservação da placenta, bem como sua utilização como chá revigorante após o parto. Na prática hospitalar essa conduta seria considerada inusitada, pois o órgão costuma ser descartado sem que a mulher seja anteriormente consultada.

[...] aí a doula, que segue bem a tradição, preparou um chá com a placenta, flores e ervas pra revigorar mesmo todas as forças. $E$ todos nós bebemos (P2)

\section{[...] colocamos a placenta numa bacia pra depois fazer o chá pra revigorar (P4)}

Com o aumento do interesse em resgatar antigas tradições, a partir dos partos naturais e humanizados, algumas mulheres brasileiras estão adotando a prática de ingerir, realizar chás ou essências com suas placentas, sob a orientação de suas doulas ou parteiras. Essa prática tem sido realizada de modo informal, empírico, pois não há estudos científicos conhecidos que comprovem os benefícios.

Parteiras europeias e algumas enfermeiras brasileiras também têm realizado esse experimento, transformando a placenta em pó para a confecção de cápsulas. Ao que tudo indica o uso terapêutico da placenta não é uma prática recente, pois existem registros procedentes da medicina tradicional chinesa que discorrem sobre o assunto desde 1578 e, na Europa, há documentos dispersos sobre a secagem da placenta e seu uso como remédio desde $1700^{18}$. 
Segundo alguns especialistas, a placenta possui muitas virtudes terapêuticas ainda pouco exploradas pela ciência. No uso empírico é considerada revigorante, anti-hemorrágica, antidepressiva e um excelente estimulador da produção de leite. É também usada no tratamento de diversas doenças das mulheres e das crianças, como por exemplo, as alergias. Atualmente, no Reino Unido, existem especialistas que oferecem treinamentos para profissionais sobre o preparo da placenta para seu uso medicinal nas mais diversas formas: cápsulas, essências, tinturas e homeopatias ${ }^{18}$. Entretanto, essa prática é pouco conhecida no Brasil.

\section{Reação familiar frente ao parto domiciliar}

As participantes relataram que, inicialmente, os familiares ficaram temerosos diante desta opção. Todavia, respeitaram a decisão. Duas participantes utilizaram o documentário "O Renascimento do Parto" para demonstrar aos seus familiares as evidências científicas que discorrem sobre a segurança dos partos domiciliares quando a gestação é de risco habitual. Após o nascimento, alguns familiares mudaram seus conceitos, conforme demonstrado abaixo:

[...] a minha mãe ficou um pouco apreensiva porque ela é enfermeira, mas respeitou a minha decisão. Depois que ele nasceu ela falou que foi a melhor experiência dela poder conhecer uma forma diferente de nascer (P5)

[...] eu tenho meio essa carinha de frágil, então ninguém achava que eu ia parir, ainda mais em casa. Isso intensificou muito a relação com a minha família (P7)

Desde a institucionalização do parto, as pessoas convivem com um modelo de assistência obstétrica predominantemente intervencionista. Por isso, acreditam que todos os recursos tecnológicos devem ser utilizados como forma de garantir a segurança das mães e dos recém-nascidos. Somente agora, com a disseminação do conhecimento de que as intervenções sobre os processos fisiológicos são mais danosas que a não intervenção é que o modelo tradicional começa a ser questionado.

O fato é que nos hospitais as mulheres devem seguir as rotinas que lhes são impostas, no tempo determinado pelos profissionais, não possuem autonomia e nem poder decisório sobre o que será realizado com ela e com o bebê. Mas isso porque culturalmente se introjetou que as parturientes são como "pacientes": passivas, leigas e devem obedecer às ordens dos profissionais: detentores do saber.

Já em casa, o papel dos profissionais é vigiar, cuidar, amparar, compartilhando a responsabilidade desse cuidado junto à gestante e sua família. Ela possui poder decisório, não há limites de tempo para mãe e bebê que estão saudáveis permanecerem juntos. Os profissionais estão ali a serviço deles, bem como seus acompanhantes de parto. Quando isso ocorre, a vivência da parturição é plena para a mulher e para todos que a assistem. E essa plenitude envolve não só a beleza do aspecto físico do nascimento em si, como também a energia emocional, espiritual e sexual que o circunda. Por isso, não é raro os familiares que participam dos partos domiciliares bem-sucedidos tornem-se fiéis disseminadores e defensores do mesmo.

\section{Considerações Finais}

Este estudo abordou a vivência de mulheres que tiveram partos domiciliares planejados e desvelou alguns motivos que as levaram a fazer essa escolha. Um dos principais motivos trata da insatisfação com o atual modelo de assistência obstétrica das instituições hospitalares.

Esse modelo é caracterizado pelo intervencionismo e pela falta de autonomia da mulher durante a parturição. A relação entre os profissionais costuma ser hierárquica com rígida divisão de papéis e frequentemente conflituosa. $O$ foco principal restringe-se ao cumprimento de rotinas e tarefas institucionais. Esse modelo serve, em parte, para os partos e nascimentos de alto risco, mas não satisfaz às expectativas de algumas gestantes de risco habitual.

Percebe-se que, nos partos domiciliares planejados, as práticas vão ao encontro do que preconiza as principais evidências científicas: a liberdade de movimento da parturiente, o uso de métodos não farmacológicos de alívio da dor, a presença do(s) acompanhantes(s) de sua escolha, o contato pele a pele com o recém-nascido sem tempo prédeterminado, o corte tardio do cordão umbilical, a amamentação sem imposições. Já nos centros obstétricos, a rotina 
é centralizada na vontade e no tempo dos profissionais de acordo com as atribuições que eles precisam cumprir. Esse modelo não possibilita a vivência plena do parir, que vai muito além do nascimento físico, mas que contempla outros aspectos transpessoais, tais como: a livre expressão da espiritualidade e da sexualidade, o resgate de práticas das tradições ancestrais, a intimidade em família sem restrições.

Com relação à prática de tradições seculares, a ingestão da placenta na crença de suas propriedades terapêuticas foi a evidência mais surpreendente durante as entrevistas, já que não há estudos, que tratem sobre o assunto, divulgados no Brasil. Essa prática não seria vista com naturalidade e, possivelmente respeito dentro de uma instituição hospitalar tradicional.

Por outro lado, constatou-se que este estudo apresentou algumas limitações. Durante as entrevistas, não houve relatos sobre as dificuldades vivenciadas, a necessidade de transferências para o hospital ou sobre a ocorrência de alguma intervenção por parte dos profissionais. É provável que as pesquisadoras não tenham explorado suficientemente essas possibilidades ou que as depoentes tenham valorizado somente os aspectos positivos de todo o processo. É importante lembrar que nem sempre os partos domiciliares, ainda que planejados, terminam sem necessitar de algum tipo de interferência profissional. Por isso, sugerem-se estudos que abordem essas possibilidades: a qualidade de capacitação dos profissionais envolvidos, bem como sobre os recursos e planejamentos que dispõem para as situações inesperadas.

Entre os dois modelos: hospitalar-tecnológico e o parto domiciliar planejado existe ainda a possibilidade do nascimento em centro de parto normal (CPN). Embora os CPN sejam reconhecidos pela OMS e pelo Ministério da Saúde como uma ótima opção para partos humanizados, ainda ocorrem dificuldades em instituí-los em algumas localidades do Brasil, especialmente no Rio Grande do Sul.

Ainda que as questões políticas, econômicas e/ou corporativas representem um entrave para a sua efetivação, o modelo tradicional de assistência obstétrica apresentado pelos hospitais deixa, gradativamente, de ser hegemônico e dá espaço para um número crescente de partos domiciliares planejados em todo o país. As mulheres atuais têm como características a busca incessante de informações, são consideravelmente mais questionadoras e exigentes quanto aos seus direitos, além de desejarem uma vivência de parto e nascimento mais saudável, plena e transformadora.

\section{Referências}

1. Instituto Brasileiro de Geografia e Estatística (IBGE). Censo demográfico 2010: resultados gerais da amostra por áreas de ponderação [Internet]. Rio de Janeiro: IBGE; c2014 [acesso 2014 Abr 7] Disponível em: http://censo2010.ibge.gov. $\mathrm{br} / \mathrm{resultados}$

2. Sanfelice CFO, Shimo AKK. Parto domiciliar: avanço ou retrocesso? Rev Gaúcha Enferm [Internet]. 2014 mar [acesso 2014 Dez 9];35(1):157-60. Disponível em: http://www.scielo.br/pdf/rgenf/v35n1/pt_1983-1447-rgenf-35-01-00157.pdf.

3. Ministério da Saúde (Brasil), Secretaria de Atenção à Saúde. Parto e nascimento domiciliar assistidos por parteiras tradicionais: o Programa Trabalhando com Parteiras Tradicionais e experiências exemplares [Internet]. Brasília (DF): Editora do Ministério da Saúde; 2010 [acesso 2014 Jul 5]. Disponível em: http://bvsms.saude.gov.br/bvs/publicacoes/ parto_nascimento_parteiras_tradicionais.pdf

4. McIntyre MJ. Safety of non-medically led primary maternity care models: a critical review of the international literature. Aust Health Rev [Internet]. 2012 May [cited 2012 Jul 29];36(2):140-7. Available from: Disponível em: http://www.publish. csiro.au/paper/AH11039.htm

5. Organização Mundial da Saúde. Maternidade segura. Assistência ao parto normal: um guia prático. Genebra: Organização Mundial da Saúde; 1996.

6. Fontanella BJB, Ricas J, Turato ER. Amostragem por saturação em pesquisas qualitativas em saúde: contribuições teóricas. Cad. Saúde Pública. 2008;24(1):17-27.

7. Ministério da Saúde (BRASIL), Conselho Nacional de Saúde. Resolução n. 466, de 12 de dezembro de 2012. Aprova diretrizes e normas regulamentadoras de pesquisas envolvendo seres humanos [Internet]. Diário Oficial da União, Brasília (DF); 13 jun 2013 [acesso 2014 jun 4]. Disponível em: http://conselho.saude.gov.br/resolucoes/2012/reso466.pdf 8. Minayo MCS. Pesquisa social: teoria, método e criatividade. Petrópolis (RJ): Vozes; 2012.

9. Pereira ALF, Progianti JM, Alves VH, organizadores. Legislação profissional e marcos regulatórios da prática assistencial da enfermeira obstétrica no Sistema Único de Saúde. Rio de Janeiro: Centro de Estudos da Faculdade de Enfermagem da UERJ; 2010. 
10. Fundação Oswaldo Cruz, Escola Nacional de Saúde Pública Sérgio Arouca. Inquérito Nacional sobre Parto e Nascimento. Nascer no Brasil: sumário executivo temático da pesquisa [Internet]. Rio de Janeiro: Fiocruz; [2012?] [acesso 2014 Dez 9]. Disponível em: http://www.ensp.fiocruz.br/portal-ensp/informe/site/arquivos/anexos/nascerweb.pdf 11. Van Gennep A. Os ritos de passagem: estudo sistemático dos ritos da porta e da soleira, da hospitalidade, da adoção, gravidez e parto, nascimento, infância, puberdade, iniciação, coroação, noivado, casamento, funerais, estações, etc.. Petrópolis (RJ): Vozes; 2011.

12. Odent M. A Cientificação do amor. Florianópolis: Momento atual; 2001.

13. Colacioppo PM, Koifmann MD, Riesco MLG, Schneck CA, Osava RH. Parto domiciliar planejado: resultados maternos e neonatais. Rev. Enf. Referência. 2010 Dez;3(2):81-90.

14. Cheyney M, Bovbjerg M, Everson C, Gordon W, Hannibal D, Vedam S. Outcomes of care for 16,924 planned home births in the United States: the midwives alliance of north america statistics project, 2004 to 2009. J Midwifery Womens Health [Internet]. 2014 Jan-Feb [cited 2014 Dez 9];59(1):17-27. Available from: http://onlinelibrary.wiley.com/doi/10.1111/ jmwh.12172/abstract;jsessionid=3B4462133B9C1AA92264D107E9269CCA.f04t02

15. Ministério da Saúde e Política Social (Espanha). Guia de prática clínica sobre cuidados com o parto normal. VitoriaGasteiz: Serviço Central de Publicações do Governo Basco; 2010.

16. Ministério da Saúde (BRASIL), Secretaria de Atenção à Saúde, Área Técnica de Saúde da Criança e Aleitamento Materno. Além da sobrevivência: práticas integradas de atenção ao parto, benéficas para a nutrição e a saúde de mães e crianças. Brasília (DF): Ministério da Saúde; 2011.

17. Ministério da Saúde (BRASIL), Secretaria de Atenção à Saúde. Portaria n. 371, de 7 de maio de 2014. Institui diretrizes para a organização da atenção integral e humanizada ao recém-nascido (RN) no Sistema Único de Saúde(SUS) [Internet]. Diário Oficial da União, Brasília (DF); 15 jun 1994 [acesso 2014 Ago 1]. Disponível em: http://bvsms.saude.gov. br/bvs/saudelegis/sas/2014/prt0371_07_05_2014.html.

18. Independent Placenta Encapsulation Network. IPEN placenta specialist consultants [Internet]. [London]: IPEN; c2014 [acesso 2014 Dez 12]. Disponível em: https://www.placentanetwork.com/ipen-placenta-specialists/

\title{
Rosimery Barão Kruno
}

Endereço para correspondência - Av. Victor Barreto, n²288, Bairro: Centro, CEP: 92010-00, Canoas, RS, Brasil.

E-mail: rosimery.kruno@unilasalle.edu.br Lattes: http://lattes.cnpq.br/7531681051849028

Tatiane Osvaldt da Silva - tati.osvaldt@gmail.com Patrícia Taís de Oliveira Trindade - patriciataistrindade@hotmail.com

\author{
Enviado em 21 de abril de 2015. \\ Aceito em 31 de outubro de 2016.
}

